\title{
La libertad religiosa en la Doctrina Social de la Iglesia
}

\author{
ÁNGEL GALINDO GARCÍA \\ Universidad Pontificia de Salamanca (España) \\ agalindoga@upsa.es
}

\begin{abstract}
Resumen
En este artículo el autor expone la peculiar trayectoria histórica de la libertad religiosa en la Doctrina Social de la Iglesia. Da inicio a su exposición con la enseñanza del Papa León XIII hasta llegar a la que es considerada como la «carta magna» de la Iglesia sobre la libertad religiosa, esto es, la Declaración Dignitatis humanae del Concilio Vaticano II. Así también se expone brevemente el desarrollo posterior o la aplicación concreta del pensamiento conciliar sobre la libertad religiosa en el magisterio de Pablo VI, Juan Pablo II y Benedicto XVI.
\end{abstract}

Palabras clave: libertad religiosa, dignidad humana, tolerancia, Estado, Iglesia.

\section{Religious freedom in the Social Doctrine of the Church}

\begin{abstract}
In this article the author explains the peculiar historical development of religious freedom in the Social Doctrine of the Church. Begins his exposition with the teaching of Pope Leo XIII to reach what is considered as the "Magna Carta» of the Church on religious freedom, ie Dignitatis Humanae Declaration of Vatican II. This also outlines the further development and practical implementation of the conciliar thinking about religious freedom in the teaching of Paul VI, John Paul II and Benedict XVI.
\end{abstract}

Key words: religious freedom, human dignity, tolerance, State, Church.

Sacerdote y Catedrático de Teología Moral de la Facultad de Teología de la UPSA. Decano de la misma Facultad, así como Director del Instituto Superior de Ciencias de la Familia (UPSA) y de la revista de Caritas Española Corintios XIII. Entre sus abundantes publicaciones destacan los libros Moral socioeconómica (1996), Voluntariado y sociedad participativa (2004), Responsabilidad social corporativa y medios de comunicación social (2008), Caridad en la verdad. Comentario a la encíclica 'Caritas in veritate' de Benedicto XVI (2010). 


\section{Introducción}

Hay otro aspecto de la vida de hoy, muy estrechamente unido con el desarrollo: la negación del derecho a la libertad religiosa. No me refiero solo a las luchas y conflictos que todavía se producen en el mundo por motivos religiosos. Aunque a veces la religión sea solamente una cobertura para razones de otro tipo, como el afán de poder y riqueza ${ }^{1}$.

Iniciamos esta reflexión con un texto de la encíclica Caritas in veritate del Papa Benedicto XVI, como reflejo de una de las preocupaciones más significativas del actual pontífice de la Iglesia. Pero, en diversos mensajes de la Jornada Mundial de la Paz, los pontífices han tratado el tema de la libertad religiosa de forma intensiva durante los últimos años ante los múltiples atentados contra ella que se están dando desde algunos fundamentalismos religiosos y laicistas. De forma especial, el último mensaje de la paz está dedicado expresamente a este tema².

La «carta magna» de la libertad religiosa que ha aportado la Iglesia a la humanidad mediante la enseñanza de su Doctrina Social es, sin duda alguna, la Declaración del Concilio Vaticano II sobre la libertad religiosa, titulada Dignitatis bumanae, «un documento sorpresivo, sorprendente y trascendental» ${ }^{3}$. El centro de nuestra reflexión sobre el tema de la libertad religiosa gira naturalmente entorno a este documento eclesial. Como es conocido, por la evolución de la Doctrina Social de la Iglesia (en adelante DSI), en sentido estricto, es decir, la que estructuralmente empieza con León XIII, la comprensión de la libertad religiosa ha tenido un trayecto peculiar para llegar a su auge, que es precisamente la Dignitatis bumanae. Y el desarrollo o aplicación concreta del pensamiento conciliar sobre la libertad religiosa ha sido llevado a cabo por Pablo VI, Juan Pablo II y Benedicto XVI.

Alrededor de la segunda mitad del siglo XIX, en la que la libertad religiosa suponía un problema para la Iglesia, puesto que la situación histórica general en Europa, y sobre todo en Italia, hacía a la Iglesia

\footnotetext{
1 Benedicto XVI: Carta encíclica Caritas in veritate, sobre el desarrollo humano integral en la caridad y en la verdad (29 de junio de 2009), n. 29.

2 Cfr. Juan Pablo II: Mensaje para la Jornada Mundial de la Paz 2002, 4-7 y 12-15; Ibíd., Mensaje para la Jornada Mundial de la Paz 2004, 8; Ibíd., Mensaje para la Jornada Mundial de la Paz 2005, 4; Benedicto XVI: Mensaje para la Jornada Mundial de la Paz. 2006, 9-19; Ibíd., Mensaje para la Jornada mundial de la Paz 2007, 5 y 14; Ibíd., Mensaje para la Jornada Mundial de la Paz. 2011. Todos disponibles en la dirección electrónica www.vatican.va.

3 J. M. DíAz Moreno: "La libertad religiosa, consideraciones desde la Declaración Conciliar y la Declaración de los Derechos Humanos”, en VV.AA., Libertad religiosa hoy en España. UPCO, Madrid 1992, 16.
} 
afrontar esta cuestión -nos referimos, concretamente, al 20 de septiembre de 1870, cuando las tropas de Víctor Manuel entraron en Roma y asediaron al antiguo Estado Pontificio, dejando al Romano Pontífice en un territorio riguroso: la llamada «cuestión romana». En este contexto, por un lado, la Iglesia estaba privada de ese derecho fundamental de la libertad religiosa y lo reclama con insistencia; pero, por otro lado, ante las exageraciones sectarias del uso que se hace del término mismo de libertad religiosa, y de las conductas políticas que pretenden apoyarse en ella, la Iglesia reacciona muy duramente y se pone a la defensiva. Ponemos sólo un ejemplo con el siguiente texto del Papa Pío IX:

(...) contra la doctrina de las sagradas letras, de la Iglesia y de los Santos Padres, no dudan afirmar: 'que es la mejor la condición de aquella sociedad en que no se le reconoce al Imperante o Soberano derecho ni obligación de reprimir con penas a los infractores de la Religión católica, sino en cuanto lo pida la paz pública'. Con cuya idea totalmente falsa del gobierno social, no temen fomentar aquella errónea opinión sumamente funesta a la Iglesia católica y a la salud de las almas llamada delirio por nuestro Predecesor Gregorio XVI de gloriosa memoria (en la misma encíclica Mirar), a saber: 'que la libertad de conciencia y cultos es un derecho propio de todo hombre, derecho que debe ser proclamado y asegurado por la ley en toda sociedad bien constituida; y que los ciudadanos tienen derecho a la libertad omnímoda de manifestar y declarar públicamente y sin rebozo sus conceptos, sean cuales fueren, ya de palabra o por impresos, o de otro modo, sin trabas ningunas por parte de la autoridad eclesiástica o civil't4.

\section{Desde León XIII hasta Pío XII, un recorrido general}

El pontificado de León XIII se extiende desde 1878 hasta 1904, un largo período que comprende el último cuarto del siglo XIX. Es la época en la que el liberalismo se afianza, penetra profundamente en todos los órdenes de la sociedad, informa las instituciones y modifica el panorama social. «Es un momento singular en la historia en el que se plantea, por primera vez conscientemente, un cambio radical de la estructura social y política del entero cuerpo de la sociedad $\rangle^{5}$.

En este contexto, León XIII comprende a la Iglesia como una sociedad jurídicamente perfecta, por lo tanto, «hay que admitir

PíO IX: Encíclica Quanta cura (8 de diciembre de 1864).

A. EsQuivias: La libertad de la Iglesia en la doctrina de León XIII, Extraído de la tesis doctoral del Dr. J. Martín de Agar, Roma 1991. 
igualmente que la Iglesia, no menos que el Estado, es una sociedad completa en su género y jurídicamente perfecta; y que por consiguiente, los que tienen el poder supremo del Estado, no deben pretender someter a la Iglesia a su servicio u obediencia» ${ }^{6}$. Esta afirmación de que la Iglesia es una sociedad jurídica perfecta implica que ella misma es una sociedad no dependiente de otra y, por consiguiente, que tiene competencias jurídicas especiales sobre sus fieles.

Por otra parte, en cuanto a la función del Estado respecto a la religión, León XIII afirma que el Estado tiene una obligación general de tutelar la religión, concretamente, «entre sus principales obligaciones debe colocar la obligación de favorecer la religión, defenderla con eficacia, ponerla bajo el amparo de las leyes, no legislar nada que sea contrario a la incolumidad de aquélla. Obligación debida por los gobernantes también a sus ciudadanos. Porque todos los hombres hemos nacido y hemos sido criados para alcanzar un fin último $\mathrm{y}$ supremo, al que debemos referir todos nuestros propósitos, y que colocado en el cielo, más allá de la frágil brevedad de esta vida (...). La primera y principal de todas ellas consiste en procurar una inviolable y santa observancia de la religión, cuyos deberes unen al hombre con Dios»?

Respecto a la religión católica, que es la «única religión verdadera», el Papa sostiene que «siendo, pues, necesaria en el Estado la profesión pública de una religión, el Estado debe profesar la única religión verdadera, la cual es reconocible con facilidad, singularmente en los pueblos católicos, puesto que en ella aparecen como grabados los caracteres distintivos de la verdad. Esta es la religión que deben conservar y proteger los gobernantes, si quieren atender con prudente utilidad, como es su obligación, a la comunidad política. Porque el poder político ha sido constituido para utilidad de los gobernados. Y aunque el fin próximo de su actuación es proporcionar a los ciudadanos la prosperidad de esta vida terrena, sin embargo, no debe disminuir, sino aumentar, al ciudadano las facilidades para conseguir el sumo y último bien, en que está la sempiterna bienaventuranza del hombre, y al cual no puede éste llegar si se descuida la religión» ${ }^{8}$.

Ahora bien, en la primera mitad del siglo XX, el magisterio de la Iglesia va aceptando la doctrina filosófico-jurídica acerca de los derechos

6 LEÓN XIII: Encíclica Inmortale Dei (1 de noviembre de 1885), n. 17. También véase Encíclica Sapientiae Christianae (10 de enero de 1890), Encíclica Nobillissima gallorum gens (8 de febrero de 1884) y Carta apostólica Praeclara gratulationis (20 de junio de 1894).

Inmortale Dei, n. 3.

8 LEÓN XIII: Encíclica Libertas praestantissimum (20 de junio de 1885), n. 16. 
fundamentales de la persona humana, lo cual hace posible la aparición en la doctrina oficial de un concepto central de la DSI: la persona humana como sujeto de derechos inalienables ${ }^{9}$, hasta llegar a la afirmación de Juan Pablo II según la cual «el hombre viviente, constituye el camino primero y fundamental de la Iglesia» ${ }^{10}$. Esta comprensión personalista se inicia con los Papas Pío XI y Pío XII, contemporáneos de los totalitarismos políticos que van a desembocar en la última guerra mundial. De esta manera se va purificando el concepto de Iglesia como sociedad perfecta expresado en la enseñanza de León XIII ${ }^{11}$.

En efecto, Pío XI en sus enseñanzas defiende la libertad religiosa de las tres formas políticas totalitarias: a los estados del fascismo, el Papa condena la ofensa de la libertad religiosa en toda Italia ${ }^{12}$, y defiende que «la libertad y el derecho son herencia de las almas, y especialmente de las almas de los jóvenes» ${ }^{13}$. Y contra el nazismo, frente a la situación preocupante de Alemania, Pío XI afirma: «la Iglesia conoce que la fe en Dios no se mantendrá por mucho tiempo pura e incontaminada si no se apoya en la fe de Jesucristo. Nadie conoce al Hijo sino el Padre, y nadie conoce al Padre sino el Hijo y aquel a quien el Hijo quisiere revelárselo (Lc 10, 22). Esta es la vida eterna, que te reconozcan a ti, unico Dios verdadero, y a tu enviado, Jesucristo (Jn 17, 3). A nadie, por lo tanto, es lícito decir: Yo creo en Dios, y esto es suficiente para mi religión. La palabra del Salvador no deja lugar a tales escapatorias: El que niega al Hijo tampoco tiene al Padre; el que confiesa al Hijo tiene también al Padre (1Jn 2, 23)» $\rangle^{14}$. El Papa recuerda que no debe olvidarse la libertad de los hijos de Dios ${ }^{15}$, e igualmente promete que «la Iglesia de Dios va a defender sus derechos y su libertad en nombre de Dios cuyo brazo no fallará» ${ }^{16}$. Del mismo modo, Pío XI condena el comunismo ateísta, porque esta ideología «ignora el verdadero origen y el propósito del Estado, y ataca los derechos, la dignidad y la libertad de la persona humana» ${ }^{17}$.

Recogemos un texto largo y elocuente en que el Papa proclama que el hombre, en cuanto persona, posee derechos concedidos por Dios y

9 J. M. Díaz Moreno: "La libertad religiosa, consideraciones desde la Declaración Conciliar y la Declaración de los Derechos Humanos", 25.

10 JUAN PABLO II: Carta encíclica Evangelium vitae, sobre el valor y el carácter inviolable de la vida humana (25 de marzo de 1995), n. 20.

11 A. Galindo García - J. Barrado VArquilla: León XIII y su tiempo. UPSA, Salamanca 2004.

12 Cfr., PíO XI: Carta encíclica Non abbiamo bisogno (29 de junio de 1931), n. 17.

13 Ibíd., n. 20.

14 PíO XI: Carta encíclica Mit brennender sorge (14 de marzo de 1937), n. 18.

15 Ibíd., n. 34.

16 Ibíd., n. 43.

17 PíO XI: Carta encíclica Divini Redemptoris (19 de marzo de 1937), n. 14. 
que deben ser tutelados contra cualquier atentado por parte de quien tuviese la intención de negarlos, abolirlos o impedir su ejercicio. Afirma Pío XI:

Sobre la fe en Dios, genuina y pura, se funda la moralidad del género humano. Todos los intentos de separar la doctrina del orden moral de la base granítica de la fe, para reconstruirla sobre la arena movediza de normas humanas, conducen, pronto o tarde, a los individuos y a las naciones a la decadencia moral. El necio que dice en su corazón: No hay Dios, se encamina a la corrupción moral (Sal 13[14], 1). Y estos necios, que presumen separar la moral de la religión, constituyen hoy legión. No se percatan, o no quieren percatarse, de que, el desterrar de las escuelas y de la educación la enseñanza confesional, o sea, la noción clara y precisa del cristianismo, impidiéndola contribuir a la formación de la sociedad y de la vida pública, es caminar al empobrecimiento y decadencia moral. Ningún poder coercitivo del Estado, ningún ideal puramente terreno, por grande y noble que en sí sea, podrá sustituir por mucho tiempo a los estímulos tan profundos y decisivos que provienen de la fe en Dios y en Jesucristo. Si al que es llamado a las empresas más arduas, al sacrificio de su pequeño yo en bien de la comunidad, se le quita el apoyo moral que le viene de lo eterno y de lo divino, de la fe ennoblecedora y consoladora en Aquel que premia todo bien y castiga todo mal, el resultado final para innumerables hombres no será ya la adhesión al deber, sino más bien la deserción. La observancia concienzuda de los diez mandamientos de la ley de Dios y de los preceptos de la Iglesia - estos últimos, en definitiva, no son sino disposiciones derivadas de las normas del Evangelio-, es para todo individuo una incomparable escuela de disciplina orgánica, de vigorización moral y de formación del carácter. Es una escuela que exige mucho, pero no más de lo que podemos. Dios misericordioso, cuando ordena como legislador: 'Tú debes', da con su gracia la posibilidad de ejecutar su mandato. El dejar, por consiguiente, inutilizadas las energías morales de tan poderosa eficacia o el obstruirles a sabiendas el camino en el campo de la instrucción popular, es obra de irresponsables, que tiende a producir una depauperación religiosa en el pueblo. El solidarizar la doctrina moral con opiniones humanas, subjetivas y mudables en el tiempo, en lugar de cimentarla en la santa voluntad de Dios eterno y en sus mandamientos, equivale a abrir de par en par las puertas a las fuerzas disolventes. Por lo tanto, fomentar el abandono de las normas eternas de una doctrina moral objetiva, para la formación de las conciencias y para el ennoblecimiento de la vida en todos sus planos y ordenamientos, es un atentado criminal contra el porvenir del pueblo, cuyos tristes frutos serán muy amargos para las generaciones futuras ${ }^{18}$. 
Por su parte, Pío XII, en sus casi veinte años de Pontificado, construye una auténtica carta de los derechos fundamentales del hombre alrededor del concepto fundamental y exigente del Estado de derecho, frente a cualquier género de totalitarismo y llega a afirmar que tutela el intangible campo de los derechos de la persona humana y hacer practicable el cumplimiento de sus deberes, debe ser obligación de cualquier poder público. En medio de la segunda guerra mundial, Pío XII reclama los derechos fundamentales de la persona humana. Respecto al tema de la libertad religiosa, en un discurso dirigido al IV Congreso Nacional de la Unión de los Juristas Italianos, afirma en tres puntos: 1) «Lo que no responde a la verdad y a la norma moral no tiene objetivamente derecho alguno a la existencia, ni a la propaganda, ni a la acción»; 2) «el no impedirlo por medio de leyes estatales y de disposiciones coercitivas puede, sin embargo, hallarse justificado por el interés de un bien superior y más universal»; y 3) «ninguna autoridad humana, ningún Estado, ninguna comunidad de Estados, sea el que sea su carácter religioso, pueden dar un mandato positivo o una positiva autorización de enseñar o de hacer lo que sería contrario a la verdad religiosa o al bien moral» ${ }^{19}$. Aquí Pío XII hace una distinción entre autonomía jurídica de los ciudadanos y autonomía moral, distinción que enlaza con la de Pío XI entre libertad de las conciencias y libertad de conciencia $^{20}$.

\section{Juan XXIII y el Concilio Vaticano II}

Nos centramos ahora en la enseñanza de Juan XXIII y en la del Concilio Vaticano II sobre la libertad religiosa y la persona humana como horizonte de comprensión. De ahí nacen los derechos y los límites posibles a esta libertad.

\subsection{Pacem in Terris, un paso decisivo para el reconocimiento de la libertad religiosa como derecho humano}

Juan XXIII integró definitivamente la tradición y la novedad al enseñar que la persona se manifiesta en la realidad de la vida social, a través de los derechos y deberes, no sólo formales y abstractos sino también sociales. Su catálogo de derechos y deberes no pretende ser

\footnotetext{
19 Pío XI: Alocución al Congreso Nacional de la Unión de Juristas Católicos Italianos (6 de diciembre de 1953), en AAS, 45 (1953), 798-799.

20 Cfr. A. De Fuenmayor: La libertad religiosa. EUNSA, Pamplona 1974, $24-26$.
} 
exhaustivo $^{21}$ y reconoce la importancia de una carta de derechos constitucionales para la vida social y política ${ }^{22}$ de la que ve un germen en la Declaración universal de los derechos del hombre, de la ONU, a pesar de sus limitaciones ${ }^{23}$. Tiene en cuenta que la libertad religiosa pertenece al foro de la conciencia de cada persona, pero también al foro externo de la sociedad, donde no se puede ejercer coacción sobre la profesión (libertad de conciencia) o la práctica de la fe (libertad de culto). Porque el orden social lo fundamenta en que todo ser humano es persona, o sea, tiene inteligencia y voluntad libre. De su ser natural brotan unos derechos universales, inviolables e inalienables ${ }^{24}$. Reconoce que el error no tiene justificación teórica para hacerse presente en la vida pública. Pero la afirmación que hace en positivo es significativa: «la convivencia civil sólo puede juzgarse ordenada, fructífera y congruente con la dignidad humana si se funda en la verdad (...). Esto ocurrirá, ciertamente, cuando cada cual reconozca, en la debida forma, los derechos que le son propios y los deberes que tiene para con los demás» ${ }^{25}$. Y a la tríada de valores «verdad, justicia y amor» le añadió el de «libertad» como dinamismo de un progreso social que lleva hasta la igualdad y la comunidad ${ }^{26}$.

Hasta ahora, lo que ha repetido la tesis tradicional del pensamiento católico era establecer que sólo la verdad tiene derechos y la verdad afecta exclusivamente a la Iglesia católica; es decir, sólo las verdades de la Iglesia católica, quien posee todas las verdades, tiene derecho de existir, mientras los errores no tienen derecho. Tesis que ha sido defendida hasta Juan XXIII, quien cambia este planteamiento radicalmente. Se trata del siguiente texto: «Importa distinguir siempre entre el error y el hombre que lo profesa, aunque se trate de personas que desconocen por entero la verdad o la conocen sólo a medias en el orden religioso o en el orden de la moral práctica. Porque el hombre que yerra no queda por ello despojado de su condición de hombre, ni automáticamente pierde jamás su dignidad de persona, dignidad que debe ser tenida siempre en cuentas ${ }^{27}$.

En este contexto de la defensa de las personas humanas, y junto a la Declaración Universal de los Derechos Humanos de 1948, que hemos

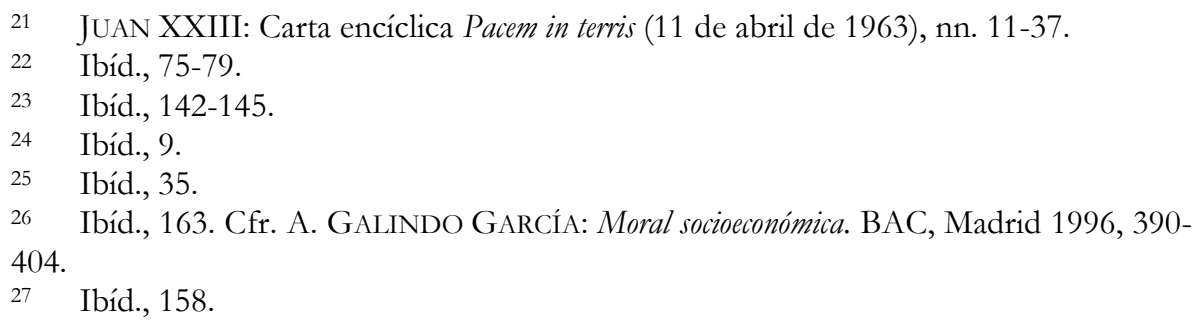


analizado en el apartado anterior, Juan XXIII en Pacem in terris realiza un análisis muy favorable al tema de los derechos humanos tal como son concebidos y proclamados por las diversas declaraciones internacionales. Tales derechos, entre los que incluye el de libertad religiosa, se basan en la dignidad que todo ser humano tiene por ser persona, es decir, inteligente y libre, y son por tanto universales, inviolables e inalienables ${ }^{28}$. Por otra parte, el Papa distingue entre el error y el errante y se servirá de ella para adelantar una formulación del derecho a la libertad religiosa, dice así el Papa: «Entre los derechos del hombre hay que reconocer también el que tiene de honrar a Dios según el dictamen de su recta conciencia y profesar la religión privada y públicamente». Esta distinción entre el error y el errante, con el congruente reconocimiento del derecho del hombre a honrar a Dios según el dictamen de su recta conciencia, se refiere al derecho de profesar la religión privada y públicamente tan sólo a las personas que obran de acuerdo con el dictamen de su conciencia, sin pensar en otros posibles titulares. Paso al que no ha llegado el Papa Juan XXIII, pero que el Concilio que él inició sí dará posteriormente.

El día 7 de diciembre de 1965 era aprobada por el Concilio Vaticano II la Declaración sobre la libertad religiosa, que se titula Dignitatis bumanae. En la votación definitiva de los Padres, 1954 votos estaban en favor, 249 en contra y 13 nulos. Con esta declaración, la Iglesia abre un nuevo horizonte, una nueva manera de ver el mundo, como ya indicamos, ya que hasta entonces, lo que enseñaba la Iglesia y la cultura del entorno era que el error no tiene derecho, y por consiguiente, no se planteaba la cuestión de la libertad religiosa. «No se exagera si se afirma que, al menos en lo que respecta a la imagen de la Iglesia en relación con el mundo en el que vive encarnada, el Concilio Vaticano II puede ser definido como el Concilio de la libertad religiosa» ${ }^{29}$. La Declaración conciliar Dignitatis humanae fue el elemento decisivo para que cambiase una cierta imagen de la Iglesia poco atractiva y hasta rechazable.

Porque, por una parte, la Declaración supone que la Iglesia, de manera definitiva, rechaza cualquier tipo de totalitarismo de signo racista, fascista, marxista o capitalista. Así, trata de integrarse en el grupo de luchadores por la libertad y por la desaparición de cualquier género de esclavitud. Y por otra parte, la libertad religiosa es un principio dinámico que debe impulsar la construcción de un nuevo y renovado modo de convivir en la Iglesia, basado en un justo y respetuoso pluralismo dentro de la máxima fidelidad a lo dogmático.

\footnotetext{
28 Cfr. Ibíd., 11-27.

29 J. M. DíAz Moreno: "La libertad religiosa, consideraciones desde la Declaración Conciliar y la Declaración de los Derechos Humanos", 17.
} 


\subsection{La comprensión conciliar del término «libertad religiosa»}

Nos acercamos ahora a estudiar la comprensión del término «libertad religiosa» desde dos niveles que configuran la vida de la Iglesia y de las personas que la forman: el humano y el divino.

a) Desde el nivel bumano: Ante todo, la Declaración conciliar quiere evitar equívocos para el término «libertad religiosa», y a tal efecto, dice en su proemio que al tratar de la libertad religiosa «pretende desarrollar la doctrina de los últimos pontífices sobre los derechos inviolables de la persona humana y sobre el ordenamiento jurídico de la sociedad $»^{30}$. Es decir, al titularse la Declaración «el derecho de las personas y de las comunidades a la libertad social y civil en materia religiosa», el Concilio quiere dejar bien claro que no trata de la libertad ni en sentido psicológico, que es presupuesto esencial de cualquier tipo de libertad y que se presupone en todo acto auténticamente responsable y humano, ni tampoco se refiere a la libertad en sentido moral y que consiste en el deber moral de buscar la verdad, la verdadera religión, sino que se trata de una libertad jurídica en la que se da una relación genuina derechodeber. El derecho radical de la persona humana a dar culto a Dios, según el dictamen de la propia conciencia y el deber del Estado de reconocer, proteger y armonizar el ejercicio de ese derecho ${ }^{31}$. Y, por consiguiente, la libertad religiosa como derecho puede ser conocido por todos los seres humanos, ya que «se han ido haciendo más patentes cada vez a la razón humana a través de la experiencia de los siglos» ${ }^{32}$. Y, por consiguiente, debe ser reconocida y respetada, tal como derecho natural por todos.

b) Desde el nivel divino: La libertad religiosa, según la noción que de ella da el Concilio, queda situada en el plano de las exigencias de la naturaleza humana. Sin embargo, es importante decir que no se ha querido apartar la luz sobrenatural de la revelación cristiana. Por el contrario, se ha tomado en conciencia en dos sentidos diversos y complementarios. Si bien se trata de verdades de razón, la Iglesia ha tenido en cuenta también, al explicarlas, la luz de la revelación, que confirma esas verdades, dándoles una extraordinaria fortaleza, pues el conocimiento es logrado también «por la Palabra revelada de Dios» ${ }^{33}$. Es

\footnotetext{
30 Concilio Vaticano II: Declaración Dignitatis humanae, n. 1.

31 Cfr. C. Corral: "Libertad religiosa", en VV.AA., Diccionario de Derecho Canónico. UPCO, Madrid 1989, 370-371.

32 Dignitatis humanae, n. 9.

33 Ibíd., n. 2.
} 
de notar que en el propio documento, la Iglesia invoca un título sobrenatural al referirse a sus enseñanzas de orden natural: «por voluntad de Cristo, la Iglesia Católica es la maestra de la verdad, y su misión consiste en anunciar y enseñar auténticamente la verdad, que es Cristo, y al mismo tiempo declarar y confirmar con su autoridad los principios de orden moral que fluyen de la misma naturaleza humana». En la segunda parte de la Dignitatis bumanae, se desarrolla ampliamente este enraizamiento de la comprensión de la libertad religiosa en la Revelación.

En este sentido, es clarificadora la reflexión de Santiago del Cura. En una ponencia reciente, expone la postura conciliar sobre el tema de la libertad religiosa como derecho fundamental del hombre; como la explicación es bien esclarecedora, citamos íntegramente la reflexión que este teólogo hace sobre el tema:

(...) no hay duda de que DH [Dignitatis humanae], con su afirmación sin reservas de la 'libertad religiosa', representa la cota más alta del magisterio eclesiástico en su doctrina sobre la 'tolerancia'. Pero a este resultado se ha llegado por un procedimiento paradójico. El concilio ha querido integrar el motivo de la tolerancia de una manera tan consecuente en su concepto de libertad religiosa que ha estimado poder renunciar a la utilización del término mismo de tolerancia, o mejor, se ha sentido obligado a evitarlo movido por una intención más profunda y por una perspectiva de horizontes más amplios.

La paradoja consiste en lo siguiente: el concilio quería abrirse y corresponder a la intencionalidad justificada de la idea moderna de tolerancia; por otro lado, tenía en contra suya la doctrina eclesial sobre la (in)tolerancia, dominante hasta la víspera misma del concilio; de ahí que se viera llevado a no introducir el concepto de tolerancia en el lenguaje de los documentos conciliares. De hecho, no se encuentra ni en DH ni en ningún otro documento, a pesar de haber sido propuesto en dos ocasiones.

¿Cómo valorar entonces la ausencia total del término 'tolerancia' y su sustitución por 'libertad religiosa' en el texto definitivamente aprobado? La doctrina magisterial y tradicional de tolerancia e incluso el concepto mismo de tolerancia fueron retenidos como un impedimento para llevar a cabo las intencionalidades del concilio en cuestiones de libertad religiosa. Pero esta eliminación no se ha de interpretar como un rechazo de las demandas modernas de tolerancia, sino más bien como su preservación y sobrepasamiento (Aufbebung) en el concepto de libertad religiosa. Por ello, la ausencia del término en $\mathrm{DH}$ no puede equipararse con un déficit del documento en cuestiones de tolerancia. Más bien implica la atribución de una importancia central a lo que se quiere hacer valer mediante el concepto, tanto en lo que el concilio rechaza como en lo que propone en cuanto postura propia. Nada extraño tiene que muchos autores hayan calificado el paso dado por el concilio Vaticano II como 'un salto 
cualitativo' y como un 'giro copernicano'. Y no hay duda de que el camino recorrido era enorme. Pues lo que de verdad se desea no es ser tolerado o soportado en las convicciones religiosas peculiares de cada uno, sino ser aceptado y reconocido en la propia diversidad. Por ello, acierta plenamente M. Seckler al afirmar que, con la declaración Dignitatis Humanae, la 'tolerancia desde arriba' se transforma en un 'derecho desde abajo'. La cuestión decisiva es ahora la libertad religiosa como un derecho, fundamentado en la dignidad de la persona humana y en la esencia del acto religioso ${ }^{34}$.

En definitiva, la noción que ofrece el Concilio acerca de la libertad religiosa tiene su origen en una abstracción del plano sobrenatural, porque se plantea de intento esa libertad en el plano de los principios de orden moral que fluyen de la misma naturaleza humana. Bien entendido que tal abstracción no significa sustracción, ni mucho menos negación del orden sobrenatural, que la Iglesia no podía en modo alguno desconocer ni dejar en la penumbra.

\subsection{Persona humana: sujeto del derecho inviolable de la libertad religiosa}

Al contemplar la libertad religiosa desde una perspectiva jurídica, el Concilio tuvo que enfrentarse con una gran interrogante que exige distinguir entre derecho positivo y derecho de la persona fundado en su dignidad, y por tanto, anterior al ordenamiento jurídico que debe reconocerlo y consagrarlo mediante las adecuadas normas. Punto bien claro para hoy, pero en su tiempo, sobre este punto hubo bastante discusión entre los padres conciliares, aquí no entramos en detalle de la parte histórica, sólo ponemos un ejemplo: «no hay todavía unanimidad sobre la ulterior explicación doctrinal, que aparece en los últimos documentos pontificios y que se expone y establece en nuestro esquema. Nuestro documento afirma que la libertad religiosa es un verdadero derecho de la persona, fundado en su dignidad humana y que debe ser reconocido como derecho civil en la sociedad civil» ${ }^{35}$. Como hemos mencionado anteriormente, los magisterios de los Papas Pío XI y Pío XII han contribuido enormemente respecto a este tema. Lo cierto es que

34 S. De CuRA: "Derecho a vivir en la verdad de la propia fe, a los 40 años de Dignitatis bumanae", en: http://leonxiii.upsam.net/seminarios/mas_informacion_ seminario05.htm. Cfr. A. GALINDO GARCÍA: Voluntariado y Sociedad participativa. UPSA, Salamanca 2006.

35 Schema declarationis de libertate religiosa. Modi a fratribus conciliaribus propositi a Secretariatu ad christianorum unitatrem fovendam examinati et textus, Typis Poliglottis Vaticanis, 1965, 21, citado en A. DE FUENMAYOR: La libertad religiosa, 22. 
Dignitatis humanae afirma solemnemente lo siguiente: la libertad religiosa como un derecho «permanece también en aquellos que no cumplen la obligación de buscar la verdad y de adherirse a ella» ${ }^{36}$. Es la persona la que es sujeto de este derecho, no es la verdad o el error. En efecto, «el derecho a la libertad religiosa no se funda en la disposición subjetiva de la persona, sino en su misma naturaleza ${ }^{37}$.

\subsection{Fundamento de la libertad religiosa: Dignitas humanae}

Como bien indican las primeras palabras de la Declaración, el fundamento de toda esta concepción del derecho de la persona humana a la libertad religiosa no es otro que la dignidad de la persona humana. En el marco de la libertad religiosa, en esta dignidad se pueden distinguir unos elementos esenciales:

-La irrenunciable responsabilidad de toda persona humana para establecer sus relaciones con Dios; esta responsabilidad exige una base de verdadera libertad.

-La relación que existe entre la persona y la verdad. La persona humana tiene una natural tendencia a buscar la verdad para vivir de ella y en ella. Pero esa verdad no puede ser conocida sino a la luz de la verdad misma. Es decir, no puede ser impuesta. Esa imposición directa o indirecta, abierta o disfrazada, destruye y deforma la verdad mima. Por consiguiente, «cada cual tiene la obligación y por consiguiente también el derecho de buscar la verdad en materia religiosa, a fin de que, utilizando los medios adecuados, se forme, con prudencia, rectos y verdaderos juicios de conciencia. Ahora bien, la verdad debe buscarse de modo apropiado a la dignidad de la persona humana y a su naturaleza social, es decir, mediante una libre investigación, sirviéndose del magisterio o de la educación, de la comunicación y del diálogo, por medio de los cuales unos exponen a otros la verdad que han encontrado o creen haber encontrado, para ayudarse mutuamente en la búsqueda de la verdad; y una vez conocida ésta, hay que aceptarla firmemente con asentimiento personal» ${ }^{38}$. Porque «Dios llama ciertamente a los hombres a servirle en espíritu y en verdad, y por eso éstos quedan obligados en conciencia, pero no coaccionados. Porque Dios tiene en cuenta la dignidad de la

\footnotetext{
36 Dignitatis bumanae, n. 2.

37 Ibíd.

38 Ibíd., n. 3.
} 
persona humana que El mismo ha creado, que debe regirse por su propia determinación y gozar de libertad ${ }^{39}$.

-El derecho de la persona humana a su propia identidad. Y en esta identidad entra, como elemento integrante y esencial, no traicionar nunca sus convicciones más íntimas y bien fundamentadas. Ya que «La dignidad humana requiere, por tanto, que el hombre actúe según su conciencia y libre elección, es decir, movido e inducido por convicción interna personal y no bajo la presión de un ciego impulso interior o de la mera coacción externa» ${ }^{40}$.

El desconocimiento de cualquiera de estos elementos integrantes de la dignidad de la persona humana, supone y lleva consigo la conculcación del derecho natural a la libertad religiosa.

\subsection{Contenido de la libertad religiosa}

a) Negativamente, el objeto o contenido de esta libertad, en cuanto derecho de la persona, es, ante todo y sobre todo, la inmunidad de coacción. Puesto que la misma expresión «libertad religiosa», por su naturaleza, excluye la coacción. Afirma la misma declaración: «Esta libertad consiste en que todos los hombres deben estar inmunes de coacción, tanto por parte de personas particulares como de grupos sociales y de cualquier potestad humana, y ello de tal manera que en materia religiosa ni se obligue a nadie a obrar contra su conciencia ni se le impida que actúe conforme a ella en privado y en público, solo o asociado con otros, dentro de los límites debidos» ${ }^{41}$. Esta inmunidad se puede entender desde dos ámbitos: por una parte, no ser forzados a actuar, en materia religiosa, en contra del dictamen de la propia conciencia. Y, por otra, no ser impedido cuando se actúa en el plano religioso según el dictamen de la propia conciencia.

Concretamente, en el n. 4 de Dignitatis humanae se enumeran los siguientes derechos que no se deben ser impedidos:

«La inmunidad para regirse por sus propias normas, para honrar a la Divinidad con culto público, para ayudar a sus miembros en el ejercicio de la vida religiosa y sustentarlos con la doctrina, y para promover instituciones en las que colaboren los miembros con el fin de ordenar la propia vida según sus principios religiosos».

\footnotetext{
39 Ibíd., n. 11.

40 Concilio Vaticano II: Constitución pastoral Gaudium et spes, n. 17.

41 Dignitatis humanae, n. 2.
} 
«El derecho de que no se les impida por medios legales o por acción administrativa de la autoridad civil la elección, formación, nombramiento y traslado de sus propios ministros, la comunicación con las autoridades y comunidades religiosas que tienen su sede en otras partes del mundo, ni la erección de edificios religiosos y la adquisición y uso de los bienes convenientes».

«El derecho de que no se les impida la enseñanza y la profesión pública, de palabra y por escrito, de su fe».

«Forma también parte de la libertad religiosa el que no se prohíba a las comunidades religiosas manifestar libremente el valor peculiar de su doctrina para la ordenación de la sociedad y para la vitalización de toda actividad humana».

b) Entendida así la inmunidad de coacción no puede afirmarse que la libertad religiosa, tal como la entiende el Concilio, sea un derecho negativo, sino como un presupuesto necesario para poder ejercer el derecho propiamente dicho, es decir, la posibilidad y facilidad de dar a Dios culto, según el dictamen de la conciencia. Por lo tanto, la libertad religiosa no se agota con este aspecto negativo, sino que se completa con estos otros de carácter positivo: «libertad para actuar conforme a la conciencia» ${ }^{42}$, «libre ejercicio de la religión en la sociedad» ${ }^{43}$, «libertad para el ejercicio de los actos internos voluntarios y libres» ${ }^{44}$. Sobre ello, la Declaración argumenta con el siguiente texto: «el ejercicio de la religión, por su propia índole, consiste, sobre todo, en los actos internos voluntarios y libres, por los que el hombre se relaciona directamente a Dios: actos de este género no pueden ser mandados ni prohibidos por una potestad meramente humana. Y la misma naturaleza social del hombre exige que éste manifieste externamente los actos internos de religión, que se comunique con otros en materia religiosa, que profese su religión de forma comunitaria» ${ }^{45}$.

Esto puede hacerse desde dos niveles que configuran la persona: el individual y el colectivo o social: a nivel individual, la Declaración afirma que «la autoridad civil debe proveer a que la igualdad jurídica de los ciudadanos, que pertenece también al bien común de la sociedad, jamás, ni abierta ni ocultamente, sea lesionada por motivos religiosos, y a que no se haga discriminación entre ellos» ${ }^{46}$. Esta exigencia de igualdad
Ibíd.
Ibíd., n. 1.
Ibíd., n. 3.
Ibíd.
Ibíd., n. 6. 
jurídica está en la entraña misma de la libertad religiosa cuando se trata de los ciudadanos, es decir, de las personas individuales, porque lo contrario sería una modalidad de coacción ejercida por el Estado a través de su ordenamiento jurídico.

A nivel colectivo es distinto y así expresa el Concilio: «Si, consideradas las circunstancias peculiares de los pueblos, se da a una comunidad religiosa un especial reconocimiento civil en la ordenación jurídica de la sociedad, es necesario que a la vez se reconozca y respete el derecho a la libertad en materia religiosa a todos los ciudadanos y comunidades religiosas» ${ }^{47}$.

En el ejercicio de este derecho de la libertad religiosa, el Concilio hace especiales declaraciones sobre las exigencias de la libertad religiosa en relación con la familia, concretamente, en el n. 5 expone lo siguiente: «Cada familia tiene derecho a ordenar libremente su vida religiosa doméstica bajo la dirección de los padres».

Los padres tienen «el derecho de determinar la forma de educación religiosa que se ha de dar a sus hijos, según sus propias convicciones religiosas».

Contra el monopolio estatal y el laicismo escolar dice: «la autoridad civil debe reconocer el derecho de los padres a elegir con verdadera libertad las escuelas u otros medios de educación, sin imponerles ni directa ni indirectamente gravámenes injustos por esta libertad de elección. Se violan, además, los derechos de los padres, si se obliga a los hijos a asistir a lecciones escolares que no corresponden a la persuasión religiosa de los padres, o si se impone un único sistema de educación del que se excluye totalmente la formación religiosa».

Dignitatis humanae habla también — dentro del contenido propio del derecho a la libertad religiosa- de los derechos de reunión y asociación: «en la naturaleza social del hombre y en la misma índole de la religión se funda el derecho por el que los hombres, impulsados por su propio sentimiento religioso, pueden reunirse libremente o establecer asociaciones educativas, culturales, caritativas y sociales ${ }^{48}$.

\subsection{Confesionalidad del Estado}

Como consecuencia de lo dicho hasta ahora, el Concilio Vaticano II establece un nuevo modo de entender la confesionalidad de los Estados. Se refiere a él en la Declaración poniendo así de manifiesto que confesio-

$\begin{array}{ll}47 & \text { Ibíd., n. } 6 . \\ 48 & \text { Ibíd., n. } 4 .\end{array}$


nalidad y libertad religiosa ni deben estar en conflicto ni por tanto han de ser necesariamente incompatibles. Es decir, después del Vaticano II lo que ya no puede admitirse es un país confesional que por ello no reconozca la libertad religiosa de sus ciudadanos. Así de tajante se expresa el n. 6 de Dignitatis humanae: «si en atención a peculiares circunstancias de los pueblos, se otorga a una comunidad religiosa determinada un especial reconocimiento jurídico de la sociedad, es necesario que al mismo tiempo se reconozca y respete a todos los ciudadanos y comunidades religiosas el derecho a la libertad en materia religiosa».

El texto parece excluir la confesionalidad doctrinal, es decir, aquella fundada en un juicio de valor del Estado acerca de cuál es la religión verdadera. Sin embargo, admite en ciertas circunstancias una confesionalidad de tipo sociológico, fundada en razones culturales, de oportunidad histórica, o en el hecho de ser la religión profesada por la mayoría de los ciudadanos $^{49}$. Así, el reconocimiento especial de que habla la Declaración, en caso de hacerse efectivo en algún Estado, no tiene por qué conducir necesariamente a éste a la declaración de su confesionalidad; podría muy bien traducirse en otras posibilidades, como por ejemplo en un simple apoyo de tipo económico. Supuesta, por tanto, la garantía de la libertad religiosa, se declare el Estado confesional o no, lo único rechazable por el Concilio es el Estado anticonfesional o ateo porque no respeta aquel derecho de las personas ${ }^{50}$.

En todo caso, en el conjunto doctrinal del Vaticano II late el deseo de libertad de la Iglesia, puesto que «entre los elementos que integran el bien de la Iglesia, más aún, el bien de la misma sociedad temporal (...) es ciertamente el más importante el que la Iglesia disfrute del grado de libertad de acción que requiere el cuidado de la salvación de los hombres (...) La libertad de la Iglesia es principio fundamental en las relaciones entre la Iglesia y los poderes públicos y todo el orden civilı ${ }^{51}$. Y, por consiguiente, en lo posible, se deben romper los lazos improcedentes donde los hubiere, de manera que la Iglesia «no pone su esperanza en privilegios dados por el poder civil; más aún, renunciará al ejercicio de ciertos derechos legítimamente adquiridos tan pronto como conste que su uso puede empañar la pureza de su testimonio o las nuevas condiciones de vida exijan otra disposición $»^{52}$. En definitiva, lo que pide el Concilio es que el Estado, sin identificarse con ninguna religión,

\footnotetext{
49 Cfr., Gaudium et spes, nn. 4, 42 y 76.

50 Cfr. Dignitatis humanae, n. 15.

51 Ibíd., n. 13.

52 Gaudium et spes, n. 76.
} 
valore, respete, garantice y tutele el derecho civil de la libertad religiosa de todos.

\subsection{Los límites en el ejercicio del derecho a la libertad religiosa}

El derecho a la libertad religiosa ha de ser reconocido «dentro de los límites debidos» ${ }^{53}$. De esos límites la Declaración en el n. 7, afirma: según el «principio moral de la responsabilidad personal y social», en el ejercicio de la libertad religiosa, deben ser respetados «los derechos de los otros, los propios deberes para con los demás y el bien común de todos». Por otra parte, la Declaración acoge la noción del orden público como uno de los límites en el ejercicio de la libertad religiosa. Aquello procura la pacífica composición de la paz pública y la custodia de la moral pública.

\section{La continuidad y la innovación de las enseñanzas conciliares en Pablo VI y en Juan Pablo II}

\subsection{Pablo VI}

Pablo VI se ocupó durante su Pontificado de la aplicación inmediata del Concilio, es decir, se dedicó a poner en práctica lo más externo e intenso de sus posibilidades.

En cuanto a lo que atañe al tema de la libertad religiosa, no ha tenido tiempo para desarrollarla, pero esto no quiere decir que haya marginado este tema. En efecto, como prueba nos encontramos con el texto siguiente en que el Papa habla sobre la libertad religiosa: «no se puede separar la necesidad de asegurar todos los derechos fundamentales del hombre, entre los cuales la libertad religiosa ocupa un puesto de primera importancia $\rangle^{54}$.

Igualmente, Pablo VI recuerda que el mandato de Cristo de anunciar el Evangelio no consiste, de ninguna manera, en la violación de este derecho fundamental a la libertad religiosa. Así, «nuestra misión, aunque es anuncio de verdad indiscutible y de salvación necesaria, no se presentará armada con la coacción exterior, sino que solamente por las vías legítimas de la educación humana, de la persuasión interior, de la

\footnotetext{
53 Dignitatis humanae, n. 2.

54 PABLO VI: Exhortación apostólica Evangelii nuntiandi (8 de diciembre de 1975), n. 39.
} 
conversación común, ofrecerá su don de salvación, respetando siempre la libertad personal y civilı ${ }^{55}$.

\subsection{Juan Pablo II}

Pero, ha sido Juan Pablo II quien trata constantemente este tema, llevando a la práctica las novedades que aporta la Dignitatis bumanae. La trayectoria personal antes de ser Papa, de vivir en un país donde carecía de libertad religiosa bajo el régimen del comunismo ha sido decisiva, tanto para la aportación de la declaración conciliar, como para, una vez llegado al Pontificado, luchar incansablemente por defender la libertad religiosa de los pueblos.

Con ocasión del $30^{\circ}$ aniversario de la Declaración Universal de los Derechos Humanos, Juan Pablo II, recién iniciado su Pontificado, escribió un mensaje al secretario general de la ONU, en el cual se refiere a la libertad religiosa: «para los creyentes, permitiendo que Dios hable al hombre, es como se puede contribuir más auténticamente a reforzar la convicción de que todo ser humano, hombre y mujer, tiene su propio destino y a hacer caer en la cuenta de que todos los derechos se derivan de la dignidad de la persona, la cual está firmemente enraizada en Dios. Deseo ahora hablar de estos derechos en sí mismos, tal y como fueron sancionados en la Declaración y más en especial de uno de ellos que ocupa, sin duda, un lugar central: el derecho a la libertad de opinión, conciencia y religión. Permitidme llamar la atención de la Asamblea sobre la importancia y la gravedad del problema que todavía hoy se siente y se padece muy agudamente. Me refiero al problema de la libertad religiosa que está en la base de todas las otras libertades y va inseparablemente unida a éstas por razón de esa dignidad de la persona humana» ${ }^{56}$.

Por otra parte, Juan Pablo II afirma que este derecho a la libertad religiosa es inviolable, es derecho natural. Por lo tanto, «Ninguna autoridad humana tiene el derecho de intervenir en la conciencia de ningún hombre. Esta es también testigo de la trascendencia de la persona frente a la sociedad, y, en cuanto tal, es inviolable. Sin embargo, no es algo absoluto, situado por encima de la verdad y el error; es más, su naturaleza íntima implica una relación con la verdad objetiva, universal e igual para todos, la cual todos pueden y deben buscar. En esta relación

55 PABLO VI: Carta encíclica Ecclesiam suam (6 de agosto de 1964), n. 69.

56 El texto íntegro en el L'Osservatore Romano, edic. española, 13-14, citado en J. M. DíAz MORENO: "La libertad religiosa, consideraciones desde la Declaración Conciliar y la Declaración de los Derechos Humanos", 32. 
con la verdad objetiva la libertad de conciencia encuentra su justificación, como condición necesaria para la búsqueda de la verdad digna del hombre y para la adhesión a la misma, cuando ha sido adecuadamente conocida $»^{57}$. Así, «la libertad religiosa, exigencia ineludible de la dignidad de cada hombre, es una piedra angular del edificio de los derechos humanos y, por tanto, es un factor insustituible del bien de las personas y de toda la sociedad, así como de la realización personal de cada uno. De ello se deriva que la libertad de los individuos y de las comunidades, de profesar y practicar la propia religión, es un elemento esencial de la pacífica convivencia de los hombres. La paz, que se construye y consolida a todos los niveles de la convivencia humana, tiene sus propias raíces en la libertad y en la apertura de las conciencias a la verdad $\iota^{58}$.

En el fondo, la libertad religiosa es una cuestión que afecta al problema esencial del hombre, es una cuestión crucial, y por ello considera el Papa que los problemas humanos más debatidos y resueltos de manera diversa en la reflexión moral contemporánea se relacionan, aunque sea de modo distinto, con un problema crucial: la libertad del hombre. No hay duda de que hoy día existe una concientización particularmente viva sobre la libertad. «Los hombres de nuestro tiempo tienen una conciencia cada vez mayor de la dignidad de la persona humana», como constataba ya la Declaración conciliar" «De ahí la reivindicación de la posibilidad para que los hombres 'actúen según su propio criterio y hagan uso de una libertad responsable, no movidos por coacción, sino guiados por la conciencia del deber' [Dignitatis humanae, n. 1]. En concreto, el derecho a la libertad religiosa y al respeto de la conciencia en su camino hacia la verdad es sentido cada vez más como fundamento de los derechos de la persona, considerados en su conjunto [cf. Redemptor hominis, n. 17; Libertatis conscientia, n. 19]»" ${ }^{60}$.

$\mathrm{Y}$ en cuanto a los límites en el ejercicio de la libertad religiosa, expresa Juan Pablo II lo siguiente: «ciertamente, la limitación de la libertad religiosa de las personas o de las comunidades no es sólo una experiencia dolorosa, sino que ofende sobre todo a la dignidad misma del hombre, independientemente de la religión profesada o de la concepción que ellas tengan del mundo. La limitación de la libertad religiosa y su violación contrastan con la dignidad del hombre y con sus derechos objetivos» ${ }^{61}$.

57 JuAn PABlo II: Mensaje de la Jornada Mundial de la Paz, 1991, n. 1

58 Ibíd., Mensaje de la Jornada Mundial de la Paz, 1988, Introducción.

59 Dignitatis humanae, n. 1.

60 JUAN PABLO II: Carta encíclica Veritatis Splendor, sobre algunas cuestiones fundamentales de la Enseñanza Moral de la Iglesia (6 de agosto de 1993), n. 31.

61 Ibíd., Redemptor hominis (4 de marzo de 1979), n. 17. 


\section{Dos palabras acerca de las enseñanzas de Benedicto XVI sobre la libertad religiosa}

Prescindiendo de los pensamientos del teólogo alemán Joseph Ratzinger - contenido que daría lugar a un trabajo más amplio-, el Pontificado de Benedicto XVI todavía no le permite forjar un sistema bien desarrollado sobre el tema de la libertad religiosa. Sin embargo, en algunas ocasiones, menciona el derecho a la libertad religiosa, y así también se acerca a la cuestión de la libertad religiosa desde diversos parámetros.

\subsection{Libertad religiosa y orden público}

Hablando sobre la relación entre libertad y verdad, el Papa alude explícitamente a la Declaración Dignitatis humanae: «el Concilio insiste ampliamente en la libertad religiosa, que debe garantizarse tanto a las personas como a las comunidades, respetando las legítimas exigencias del orden público. Y esta enseñanza conciliar, después de cuarenta años, sigue siendo de gran actualidad. En efecto, la libertad religiosa está lejos de ser asegurada efectivamente por doquier: en algunos casos se la niega por motivos religiosos o ideológicos; otras veces, aunque se la reconoce teóricamente, es obstaculizada de hecho por el poder político o, de manera más solapada, por el predominio cultural del agnosticismo y del relativismo» ${ }^{62}$.

A los cristianos que viven bajo las persecuciones, pero luchando por la libertad religiosa, el Papa se siente «más cerca que nunca de todos esos cristianos que sufren persecuciones a causa de la fe, su testimonio, del que diariamente recibimos noticias, y sobre todo el sacrificio de quienes han sido asesinados - reconoce-, es para nosotros motivo de edificación y nos motiva a un compromiso evangélico cada vez más sincero y generoso».

El sucesor de Pedro dirige su pensamiento «particularmente a aquellas comunidades que viven en los países en los que falta la libertad religiosa o sufren de hecho múltiples restricciones, a pesar de que se afirme sobre el papel». A estos cristianos, dice, les envío su «afectuoso aliento para que perseveren en la paciencia y en la caridad de Cristo, semilla del Reino de Dios, que viene, es más, que ya está en el mundo. A cuantos trabajan al servicio del Evangelio en esas difíciles situaciones, deseo expresarles mi más profunda solidaridad en nombre de toda la

62 Angelus, 4 de diciembre de 2005. 
Iglesia, y al mismo tiempo asegurarles mi cotidiano recuerdo en la oración» ${ }^{63}$.

\subsection{Libertad religiosa y el auténtico desarrollo}

En la encíclica Caritas in veritate insiste en la aportación positiva de las religiones a favor del desarrollo. «La religión cristiana y las otras religiones pueden contribuir al desarrollo solamente si Dios tiene su lugar en la esfera pública, con específica referencia a la dimensión cultural, social, económica y, en particular, política. La doctrina social de la Iglesia ha nacido para reivindicar esa 'carta de ciudadanía' de la religión cristiana» $^{64}$.

De este texto se deduce con claridad que la DSI desde el principio ha buscado, como hemos visto más arriba, un lugar dentro de la res publica ante la expulsión que las fuerzas oscurantistas liberales hicieron de la vida social desde el siglo XIX. En este sentido, el Papa insiste en que la exclusión de la religión del ámbito público impide el encuentro entre las personas y su colaboración para el progreso de la humanidad. Como consecuencia la sociedad se empobrece y se convierte en agresiva y opresora.

\subsection{La paz y la libertad religiosa}

En la Jornada Mundial de la paz de $2011^{65}$, Benedicto XVI relaciona la libertad religiosa con la paz ante los acontecimientos de opresión religiosa, en particular de la religión cristiana, que está creciendo en el mundo tanto desde el fundamentalismo musulmán como desde el mundo laicista. Desde las dificultades que el cristianismo tiene para expresar su fe, el Papa fundamenta la libertad religiosa en relación con el valor de la persona humana: «En efecto, en la libertad religiosa se expresa la especificidad de la persona humana, por la que puede ordenar la propia vida personal y social a Dios, a cuya luz se comprende plenamente la identidad, el sentido y el fin de la persona. Negar o limitar de manera arbitraria esa libertad, significa cultivar una visión reductiva de la persona humana, oscurecer el papel público de la religión; significa generar una sociedad injusta, que no se ajusta a la verdadera naturaleza

\footnotetext{
63 Angelus, 26 de marzo de 2006.

64 BENEDICTO XVI: Caritas in veritate, n. 56.

65 Benedicto XVI: Mensaje para la celebración de la XLIV Jornada Mundial de la Paz. (1 de enero de 2011), "La libertad religiosa, camino para la paz".
} 
de la persona humana; significa hacer imposible la afirmación de una paz auténtica y estable para toda la familia humana» ${ }^{66}$.

Entre los factores más significativos de la relación entre construcción de la paz y libertad religiosa, encontramos en este Mensaje la necesidad del ejercicio de una libertad religiosa que garantice el respeto recíproco, cuyo origen está en la familia considerada como escuela de libertad y de paz. Por esta razón, el derecho a la libertad religiosa ocupa un lugar peculiar entre los derechos y libertades fundamentales que se enraízan en la dignidad de la persona humana.

\subsection{Libertad religiosa y laicismo}

La presencia de un renacimiento del laicismo, como en la época rancia del siglo XIX, impulsa a Benedicto XVI a recobrar el mensaje de la DSI sobre la dimensión pública de la religión fundada en la racionalidad, ya que la vida religiosa no se agota en la dimensión individual del hombre. El laicismo suele utilizar la religión e instrumentalizarla para adquirir su interés de grupo. De esta manera, el Papa es consciente de que «La instrumentalización de la libertad religiosa para enmascarar intereses ocultos, como por ejemplo la subversión del orden constituido, la acumulación de recursos o la retención del poder por parte de un grupo, puede provocar daños enormes a la sociedad ${ }^{67}$.

Benedicto XVI, fiel a su reflexión teológica anterior, distingue entre laicismo y laicidad en referencia a lo que es una cuestión de justicia y de civilización: el fundamentalismo y la hostilidad contra los creyentes comprometen la laicidad positiva de los estados. Para ello, afirma «no se ha de olvidar que el fundamentalismo religioso y el laicismo son formas especulares y extremas de rechazo del legítimo pluralismo y del principio de laicidad. En efecto, ambos absolutizan una visión reductiva y parcial de la persona humana, favoreciendo, en el primer caso, formas de integrismo religioso y, en el segundo, de racionalismo» ${ }^{68}$.

Pero el Pontífice desde el espíritu futurista, realista y positivo ofrece soluciones a este problema de la opresión de la religión que nace del laicismo actual: en orden a la solución de los conflictos y conseguir una sociedad en paz es necesario potenciar el diálogo entre instituciones civiles y religiosas $^{69}$, vivir en el amor y en la verdad ${ }^{70}$, el diálogo como

\footnotetext{
66 Ibíd., n. 1.

67 Ibíd., n. 7.

68 Ibíd., n. 8.

69 Ibíd., n. 9.

70 Ibíd., n. 10.
} 
búsqueda en común ${ }^{71}$, favorecer la verdad moral en la política y en la diplomacia $^{72}$ y más allá del odio y del prejuicio ${ }^{73}$.

Según el cardenal, actualmente Papa Benedicto XVI, tres son las posturas a tener en cuenta en el dialogo con el mundo de la laicidad. En primer lugar, es necesario crear un diálogo abierto y franco, entre los representantes de la fe cristiana y los laicos de diversos sectores para conocer bien el concepto de «laico» y de «cristiano». La estructura de este diálogo se dedicará a estudiar el relativismo occidental como uno de los grandes problemas de la situación ética actual. El segundo punto se refiere a la división confesional de Europa. Habrá que encontrar entre los Estados una forma de paz moral y no solo jurídica con la que se ha de entender que si es verdad que en el ámbito de la fe existe división, sin embargo hay unos fundamentos morales comunes de índole natural como punto de referencia para lograr la unidad. En tercer lugar, es preciso retomar el problema de la compatibilidad de la tradición cristiana con el concepto de libertad desarrollado por la modernidad y por el laicismo. Según el cardenal es preciso distinguir entre laicismo y laicidad y, si esto es así, es importante superar el malentendido concepto del individualismo de la libertad ${ }^{74}$.

\section{Conclusión}

En definitiva, y de acuerdo a lo expuesto en este artículo, puede decirse que en el pensamiento de la Iglesia, con sus enseñanzas del Magisterio, la libertad religiosa, como derecho fundamental de la persona humana, ocupa un puesto de preeminencia por ser expresión tangible de la misma conciencia del hombre. En este sentido, la violación de este derecho constituye una de las ofensas e injusticias perpetradas contra la persona en su esencialidad de ser en libertad. Por ello, al buscar y luchar por el reconocimiento y la garantía de este derecho, la Iglesia no sólo, ni quizá principalmente, busca encontrar un espacio de libertad para proseguir en su misión evangelizadora, sino que encuadra esta libertad en un marco más amplio. «La libertad religiosa y su reconocimiento y protección supone la base del reconocimiento y la garantía de otras

\footnotetext{
$71 \quad$ Ibíd., n. 11.

72 Ibíd., n. 12.

73 Ibíd., n. 13.

74 Cfr. Coloquio entre el cardenal Joseph Razinger y Ernesto Galli, en Il Foglio, 27-28 de octubre de 2004.
} 
libertades y derechos fundamentales» ${ }^{75}$, porque es imposible que subsista una auténtica libertad de pensamiento, de opinión, de asociación, de reunión, sin el derecho fundamental a que el hombre cumpla, individual y asociadamente, con sus deberes religiosos, tal y como se los dicta su propia conciencia.

Sumario: Introducción; 1. Desde León XIII hasta Pío XII, un recorrido general; 2. Juan XXIII y el Concilio Vaticano II; 2.1. Pacem in terris, un paso decisivo para el reconocimiento de la libertad religiosa como derecho humano; 2.2. La comprensión conciliar del término «libertad religiosa»; 2.3. Persona humana: sujeto del derecho inviolable de la libertad religiosa; 2.4. Fundamento de la libertad religiosa: Dignitas humanae; 2.5. Contenido de la libertad religiosa; 2.6. Confesionalidad del Estado; 2.7. Los límites en el ejercicio del derecho a la libertad religiosa; 3. La continuidad y la innovación de las enseñanzas conciliares en Pablo VI y en Juan Pablo II; 3.1. Pablo VI; 3.2. Juan Pablo II; 4. Dos palabras acerca de las enseñanzas de Benedicto XVI sobre la libertad religiosa; 4.1. Libertad religiosa y orden público; 4.2. Libertad religiosa y el auténtico desarrollo; 4.3. La paz y la libertad religiosa; 4.4. Libertad religiosa y laicismo.; Conclusión. 